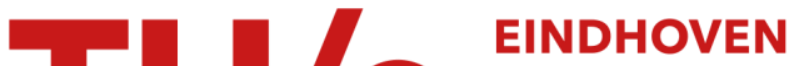

\section{Round-the-year security analysis with bottleneck ranking for interconnected power systems with large-scale wind power}

\section{Citation for published version (APA):}

Ciupuliga, A. R., Gibescu, M., Pelgrum, E., Jacobs, P. G. H., Jansen, C. P. J., \& Kling, W. L. (2010). Round-theyear security analysis with bottleneck ranking for interconnected power systems with large-scale wind power. In Proceedings of the IEEE PES Innovative Smart Grid Technologies Conference Europe (ISGT Europe 2010), 1113 October 2010, Gothenburg, Sweden (pp. 1-8). Institute of Electrical and Electronics Engineers. https://doi.org/10.1109/ISGTEUROPE.2010.5638973

DOI:

10.1109/ISGTEUROPE.2010.5638973

Document status and date:

Published: 01/01/2010

\section{Document Version:}

Publisher's PDF, also known as Version of Record (includes final page, issue and volume numbers)

\section{Please check the document version of this publication:}

- A submitted manuscript is the version of the article upon submission and before peer-review. There can be important differences between the submitted version and the official published version of record. People interested in the research are advised to contact the author for the final version of the publication, or visit the $\mathrm{DOI}$ to the publisher's website.

- The final author version and the galley proof are versions of the publication after peer review.

- The final published version features the final layout of the paper including the volume, issue and page numbers.

Link to publication

\section{General rights}

Copyright and moral rights for the publications made accessible in the public portal are retained by the authors and/or other copyright owners and it is a condition of accessing publications that users recognise and abide by the legal requirements associated with these rights.

- Users may download and print one copy of any publication from the public portal for the purpose of private study or research.

- You may not further distribute the material or use it for any profit-making activity or commercial gain

- You may freely distribute the URL identifying the publication in the public portal.

If the publication is distributed under the terms of Article 25fa of the Dutch Copyright Act, indicated by the "Taverne" license above, please follow below link for the End User Agreement:

www.tue.nl/taverne

Take down policy

If you believe that this document breaches copyright please contact us at:

openaccess@tue.nl

providing details and we will investigate your claim. 


\title{
Round-the-year Security Analysis with Bottleneck Ranking for Interconnected Power Systems with Large-Scale Wind Power
}

\author{
A. R. Ciupuliga, Graduate Student Member, IEEE, M. Gibescu, Member, IEEE, E. Pelgrum, \\ P.G.H. Jacobs, C.P.J Jansen and W. L. Kling, Member, IEEE
}

\begin{abstract}
The ongoing liberalization process in Europe together with the growing penetration of renewable energy sources (RES), e.g. wind power, require an internationally oriented transmission planning approach that considers the increased uncertainties in terms of trade, location of generation and output of intermittent RES.

This paper identifies and ranks bottlenecks, which is the first step of the transmission expansion planning process of interconnected transmission grids. A round-the-year approach is adopted by combining market simulations with static security analysis. Many combinations of load and generation (including renewables) are created and analyzed, using unit dispatch based on cost optimization. For each combination the branch loadings are determined for normal and contingency situations. A statistical risk-based approach for ranking the most severe bottlenecks is developed. The method is illustrated on a modified New England test system where wind power was added at several buses. A regional analysis and a detailed per-area analysis are presented.
\end{abstract}

Index Terms-- bottleneck ranking, load flow analysis, market simulations, multi-criteria analysis, round-the-year approach, power generation dispatch, transmission planning, wind energy.

\section{NOMENCLATURE}

$\mathrm{TSO}=$ Transmission System Operator

RES=Renewable Energy Sources

\section{INTRODUCTION}

$\mathrm{T}$ HE ongoing liberalization process in Europe and the rest of the world has led to the emergence of energy markets, facilitating international trade between countries. Consequently, inter-area power exchanges have significantly increased and further growth can be foreseen. At the same time, the increased penetration of intermittent renewables in

The research leading to these results has received funding from the European Community's Seventh Framework Programme (FP7/2007-2013) under grant agreement $\mathrm{n} 219123$ (REALISEGRID project).

A. R. Ciupuliga, and M. Gibescu are with Delft University of Technology, Department of Electrical Sustainable Energy, Group of Power Systems, Mekelweg 4, 2628 CD Delft, The Netherlands (e-mail: A.R.Ciupuliga@tudelft.nl, M.Gibescu@tudelft.nl).

E. Pelgrum, P.G.H. Jacobs and C.P.J Jansen are with TenneT TSO B.V. (e-mail: E.Pelgrum@tennet.org, P.Jacobs@tennet.org, K.Jansen@tennet.org)

W. L. Kling is with Eindhoven University of Technology (e-mail: w.1.kling@tue.nl) the European grid has been impressive in recent years and further grid-connections of large-scale onshore and offshore wind power are planned in order to meet Europe's environmental targets for 2020 and further.

Both developments mentioned above extend the uncertainty of the power flows in the system due to the variability and limited predictability of wind power and require a more international orientation and coordination of the planning process. Furthermore, increased uncertainties (trade, location of generation and output of renewables) must be incorporated during the planning process.

Most of the existing transmissions planning methods make use of a worst-case approach [1]: a power flow analysis is performed for one or a small number of scenarios, which should stand for all possible combinations of load, generation and interchange. For choosing the worst cases scenarios the TSOs rely on scenarios of load growth, generation development, and power exchanges evolution. For each scenario, they have to take into account the stochastic aspects of the phenomena (load patterns; generating units' availability, wind and hydro conditions) and determine the worst cases based on experience.

With the increased uncertainty and the many assumptions necessary for the analysis, a large number of 'worst cases' is likely to exist, which must be captured in order to achieve a robust planning under a variety of possible scenarios. Hence some TSOs (in France and Spain) and projects of European interest (the EWIS and TRADEWIND studies) have started to adopt more probabilistic methods for planning the transmission grid as shown in [1].

In Spain [2] there are about 400 scenarios generated to identify all plausible operating conditions defined as combinations of load conditions, generation profile, and network status, including extreme situations. Each scenario has associated a probability occurrence. Static security analysis (via optimal power flow) and dynamic analysis (via transient stability tool) are performed. In the end indices are calculated and charts created for facilitating the decision making process.

In France [1] load flow analyses performed via probabilistic methods are mainly used for the $400 \mathrm{kV}$ network and in those cases the network flows are influenced by the generation plan and the cross-border flows. Different load situations are forecasted (winter peak, winter off-peak, summer peak, summer off-peak, inter-season peak), different scenarios are also established for exchanges on interconnections, thousands 
of generation scenarios playing on availability of the different units and on wind level on French wind areas are sampled and constraints are detected in all situations and computed statistically.

Both French and Spanish approaches however do not consider the chronological aspect (inter-temporal constraints when scheduling resources over a given time horizon) and the correlation between load and wind inputs based on measurement data.

The European Wind Integration Study (EWIS) [3] adopted a round the year approach using a market simulations tool that considers transmission constraints via a PTDF (Power Transfer Distribution Factor) matrix. However, while here the chronological and correlation aspects are considered, the security analysis was performed only on a small number of critical cases at European level, selected after analysing the output of the market simulations. Similarly TradeWind [4] used a DC optimal power flow tool and considered the European transmission grid only with its interconnectors. Generation capacity forecast for one year was an input and the tool determined the optimum power output of all generators subjected to transmission constraints; the power flow on all lines was also computed.

At international level, when there are many load and wind speed time series for the various countries that participate in a regional transmission expansion study chronology and correlation become even more important than at national level.

To this purpose, a probabilistic approach combining chronological market simulations and static security analysis to deal with uncertainties was introduced in [5] and is proposed and further developed in this work. In order to handle the increased uncertainty of power flows in the system many combinations of load, conventional generation and renewables will be created and analyzed, using unit dispatch based on cost optimization. The correlation aspect is also considered by using simultaneous load and wind speed measurements. For each combination of load and generation the branch loadings are determined for normal and contingency situations via load flow analysis. Subsequently, criteria are developed to rank the most severe bottlenecks which will become the top problems to be solved via reinforcement. This approach does not consider voltage constraints. As for speeding up the calculations a DC contingency analysis is used, the voltage limitations will be neglected. Moreover, the target of this approach is the interconnected transmission grid, and it is assumed that each TSO solves locally its own internal voltage problems.

By contrast with the other approaches, our method has the advantages of considering both chronological and correlation aspects within the market simulations and performing after that security analysis for all the simulated hours. Thus, this method is adequate for security analysis at regional level.

The paper is structured in two main parts. First, the round the year security analysis and bottleneck identification method will be explained together with the proposed ranking criteria. Secondly a validation of the method is illustrated on a modified New England test system. Last but not least conclusions are presented.

\section{METHOD FORMULATION}

\section{A. Round the Year Approach}

Fig. 1 illustrates the basic steps of the transmission expansion planning process underlining the need to also consider the uncertainties introduced by wind power. The methodology is focused on the first steps of the planning process, namely on the power system security analysis part which refers to finding transmission grid bottlenecks and deciding which are the most critical grid elements. However we adopt a round the year security analysis by combining market simulations with load flow analysis.

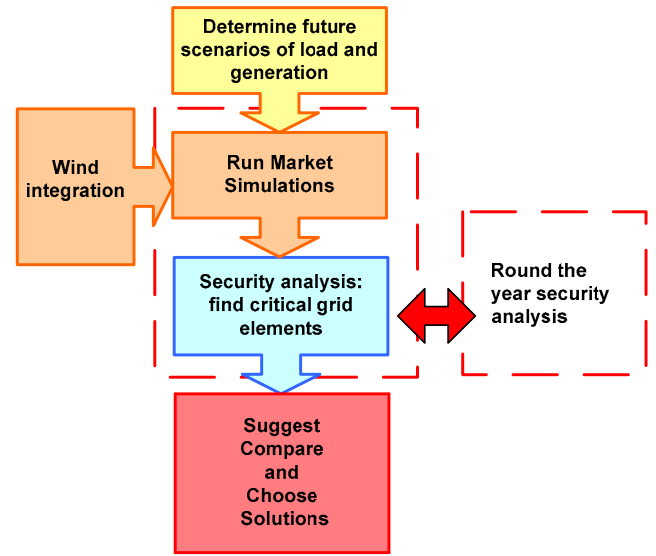

Fig. 1. Transmission expansion planning process with wind integration

Instead of performing load flow analysis for only a few worst cases, this method proposes to perform it for each hour of the year. Such a method has the advantage of clearly highlighting the structural rather than incidental bottlenecks. Moreover, since this method is based on historical wind speed time series per location, it is expected that analyzing one year (or more) of data will automatically capture all worst-cases, together with their probability of occurrence.

\section{1) Market simulations}

Establishing equilibrium between the generation and demand of electricity depends on many parameters such as availability of primary energy source, prices of fuel, bidding strategies etc. The way generation covers the demand during a certain period can be modeled with the help of market simulations. The implicit assumption is that the market operates perfectly: the system marginal price is set by the operating cost of the most expensive unit on-line during a given time period. For the implementation of the proposed method a probabilistic multi-area, multi-fuel chronological simulation model is needed that can handle technologies such as combined heat and power, energy storage, wind power and hydro power.

In the method validation section we made use of a tool called Powrsym3 [6] that has all the above mentioned features. Unit outages are modeled using a Monte Carlo method. The power system operation is simulated by the means of a total system cost minimization (including fuel costs and emission penalties) in user-definable sequential time steps, while taking into account many technical constraints of 
the system such as minimum up and down times of power plants, ramp rates of power plants, fuel costs, start-up costs etc. In the current study 1-hour time steps are adopted. The model is fully adapted to handle systems with large-scale wind generation; multiple, chronological, correlated wind power production time series can be input to the model. In addition, in order to accurately simulate production cost, unit maintenance can be scheduled and system reliability statistics can be calculated.

The presented method does not depend on a specific software tool, which means that also tools with similar characteristics can produce a valid output to be further used in the security-analysis method.

In the market calculations only the inter-area transmission capacities allocated to the market are considered, while countries are seen as a "copper-plate". Hence it is important to see what the real power flows in the grid are using a detailed network model.

\section{2) Security analysis}

The real power flows that may occur in the network as a result of the generation and load pattern obtained from the market simulations are determined via security analysis. Given the load power consumption at all buses of the electric power system and the generator power production at each power plant, the power flow through each line and transformer of the interconnected network must be determined for different topologies of the network. The flows in the network are determined for operation of the grid with all $\mathrm{N}$ elements, with $\mathrm{N}-1$ or, for some specific cases, with N-2 elements in service. The load flow analyses are repeated for every hour of the year, each with its own operating point with different values for load and generation in the nodes of the network.

This process implies a large number of calculations to be performed with specialized load-flow analysis software (such as PSS/e). The results are also numerous and it is important to be able to process them in a structured manner. Hence, there is a need to make a compromise between precision and speed. A combined AC-DC approach will be used, by performing an $\mathrm{AC}$ load flow for the normal operating situations (with all $\mathrm{N}$ elements) and DC contingency analysis for the N-1 and N-2 states. It is assumed that the voltage problems are solved locally, and therefore the DC load flow can be used as it also gives a good approximation of the AC load flow [5].

\section{3) Coupling market simulation and load flow analysis}

In order to be able to perform the load flow calculations for a given moment in time, first generation and load must be specified at the nodes of the corresponding grid. It should be mentioned that when one plans for a distant year in the future, many uncertainties regarding the location of power plants and of loads arise. Hence a set of assumptions must be made in the process of distributing load and generation in the network nodes. These assumptions may differ from case to case depending of the data availability [5], [7] and they are not the subject of this paper. The nodal distribution has to be done repeatedly, for all the hours in the year. For each hour, load and generation are distributed in the grid nodes and then security analysis is performed and finalized with an output report. Therefore an automated process must be created for allowing a rapid and continuous execution of all the steps. It is important that the load-flow tool can be automated.

Fig. 2 illustrates the implementation of the proposed method, showing the interaction between market simulations and security analysis. The market simulations have two inputs, $1 \mathrm{a}$ and $1 \mathrm{~b}$. Input $1 \mathrm{a}$ contains the generating units database (generation technology, heat rates, emission penalties, ramp up and ramp down rates, start-up costs, fuel costs), wind series (average hourly wind power production) for the study period and inter-area flow constraints. Input $1 \mathrm{~b}$ is the load data for the study period, as average hourly values; the load data is also an input for the security analysis.

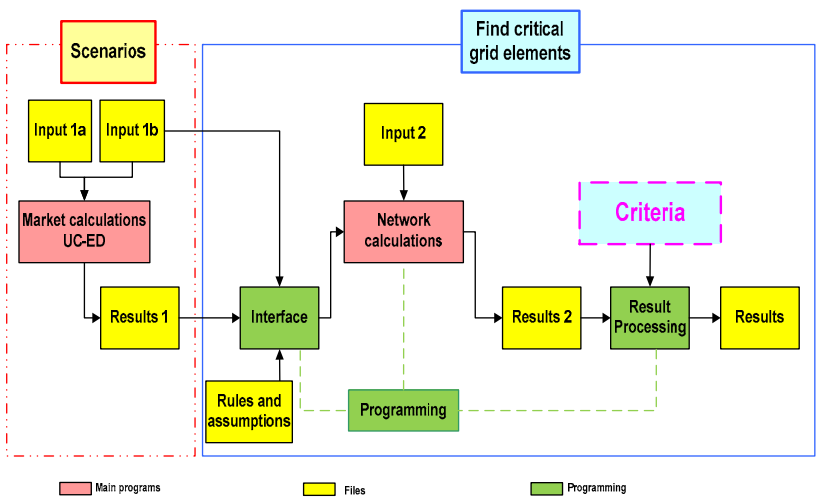

Fig. 2. Implementation block diagram

The output of the market simulations (Results 1) is the hourly status and loading of each generation unit (including wind power production) as well as the hourly programmed interchange between different areas. Results 1 together with Input $1 \mathrm{~b}$ are further processed via an interface where specific rules and assumptions for distributing load and generation into the nodes of the grid are made and sent as an input to the loadflow analysis tool together with Input 2 which is the model of the network (topology, transformer and line parameters). This process repeats for each hour of the study period and the output is Results 2 consisting of hourly loading of grid elements for base case and contingency cases.

Because of the large amount of data these results have to be post-processed using ranking criteria for choosing the weakest links in the network in order to present results that can contribute effectively to the decision-making process.

\section{B. Bottleneck ranking process}

The criteria for choosing the weakest links in the network are developed based on a statistical analysis of the results. Whereas the time dimension is absent from the classical snapshot method, in the proposed method it will play an important role within the severity ranking process. Moreover, since more aspects participate in defining the results regarding the severity of a bottleneck, a multi-criteria ranking method will be adopted (see Fig. 3). Bottlenecks will be ranked firstly per network status situation (N, N-1 and $\mathrm{N}-2)$, then per generation and load scenario, and last but not least aggregated for more scenarios. The ranking will be done according to the calculated severity indices. 
In subsection 1), the criteria that will be considered in the decision process will be illustrated. After that, the multicriteria ranking method will be explained more in detail in subsection 2) including the calculation of the severity indices.

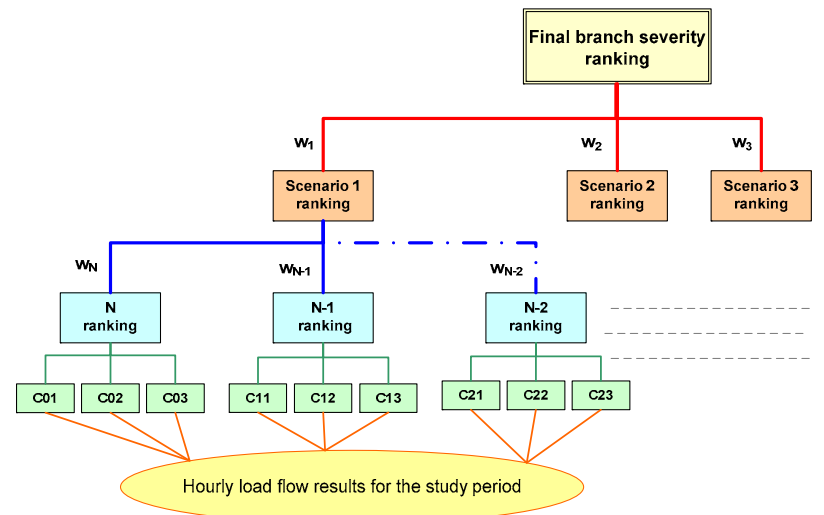

Fig. 3. Multi-criteria bottleneck ranking

\section{1) Bottleneck ranking criteria}

In the following paragraphs criteria that can be useful in the bottleneck ranking process and expansion planning decisions will be defined. These criteria are formulated for the $\mathrm{N}, \mathrm{N}-1$ and the N-2 situations.

\section{a) The normal situation}

The criteria that will be examined are:

a C01: branch loading median for the overloaded hours

a C02: total number of overloaded hours,

- C03: maximum loading of overloaded equipment

Fig. 4 i) shows an example of a load-duration curve for a given branch.

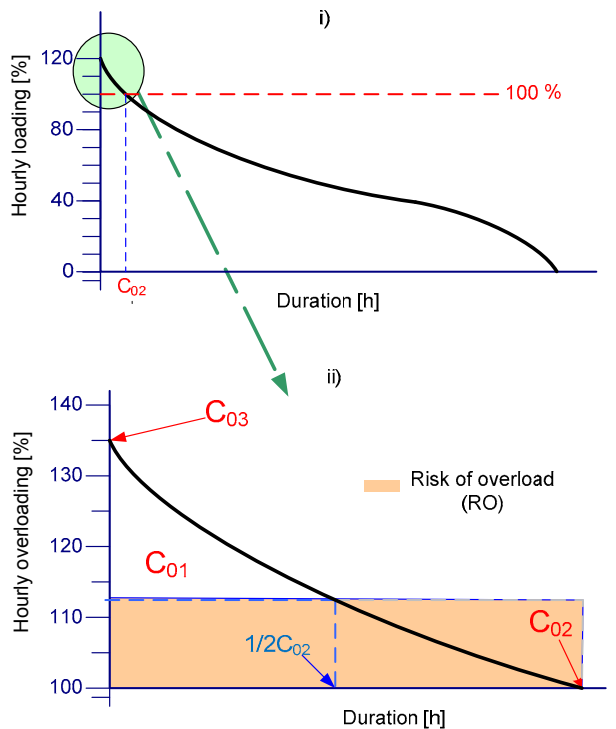

Fig. 4 i) Load-duration curve for a branch; ii) Hourly overloading-duration curve for a branch with highlighting of criteria and of risk of overload

A load duration curve is similar to a load curve but the load data is ordered in descending order of magnitude, instead of chronologically. With such a curve it can be easily visualized how frequently values are very high or very low. Our interest is in overloads that occur when the load is higher than a percentage of the element's rated capacity as agreed by all the involved TSOs. It will be considered that an overload occurs above $100 \%$ rated capacity. Hence from the previous curve we extract only the first part with loadings over 100\% rated capacity. The resulting curve can be named hourly overloading - duration curve of a branch, as illustrated in Fig. 4 ii). The three criteria are also depicted in this figure.

\section{b) The $N-1$ situation}

The criteria that will be examined are:

C11: branch loading median for the overloaded hours

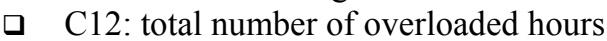

- C13: maximum loading of overloaded equipment

a C14: total number of branches that can be congested due to a given branch being taken out

a C15 the total number of branches that if taken out cause the congestion of a given branch

For each simulated hour there are many N-1 contingency cases and therefore the same number of loading values for each transmission element. Hence it is important to decide on how the results are to be interpreted. To this purpose we shall look only at the maximum hourly loading for each transmission element during the N-1 contingency.

$$
\begin{aligned}
& \text { Max_hourly_loading }{ }_{\mathrm{i}, \mathrm{t}}=\operatorname{Max}\{\text { load branch i in hour } \mathrm{t} \text {, during N-1 }\},(1) \\
& t \in \text { study period }
\end{aligned}
$$

Using this value, the maximum hourly loading - duration curve can be obtained as illustrated in Fig. 5, for each branch. Criteria $\mathrm{C} 11, \mathrm{C} 12$ and $\mathrm{C} 13$ are indicated in the figure.

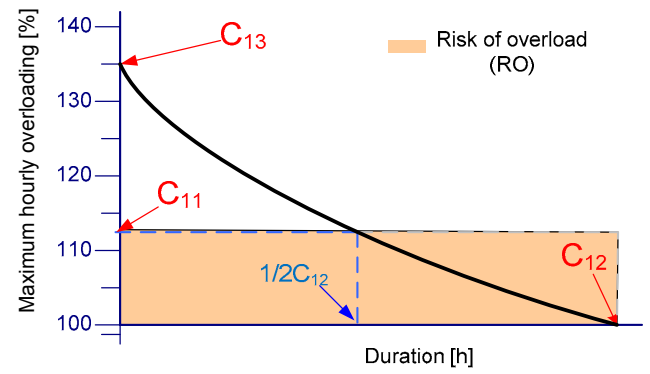

Fig. 5 Maximum hourly overloading-duration curve for a branch with highlighting of criteria and of risk of overload

Criterion $\mathrm{C} 14$ is calculated as the sum of all the branches that were congested in the study period due to the absence of branch $i$. Similarly, C15 is calculated as the sum of all branches that caused the congestion of branch $i$ in the study period, if they were switched off during N-1 contingency analysis.

\section{c) The $N$-2 situation}

The criteria that will be examined are:

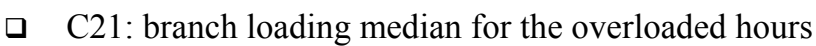

- C22: total number of overloaded hours,

- C23: maximum loading of overloaded equipment

These criteria are defined similarly to $\mathrm{C} 11, \mathrm{C} 12$ and $\mathrm{C} 13$ by considering the maximum hourly loading-duration curve for N-2. 


\section{2) Risk of overload and severity ranking of bottlenecks}

For each of the three situations $(\mathrm{N}, \mathrm{N}-1, \mathrm{~N}-2)$ the same procedure will be applied.

The severity ranking index of a branch for a situation is given by the risk of overload for that branch. The risk of overload is computed as the product between the total overloaded hours and the branch loading median for the overloaded hours minus the $100 \%$ overload threshold. Hence the risk of overload for branch $i$ during $\mathrm{N}$ situation $\left(R O_{N, i}\right)$ is:

$$
\begin{aligned}
& R O_{N, i}=\left(C 01_{i}-100\right) \cdot C 02_{i}[(\%) \text { of rated capacity } \cdot \text { hours }], \\
& i=1 . . N_{B}
\end{aligned}
$$

and is illustrated in Fig. 4 ii).

Similarly the risk of overload for a branch during N-1 contingency is illustrated in Fig. 5 and given by the formula:

$$
\begin{aligned}
& R O_{N-1, i}=\left(C 11_{i}-100\right) \cdot C 12_{i}[(\%) \text { of rated capacity } \cdot \text { hours }], \\
& i=1 . . N_{B}
\end{aligned}
$$

and the risk of overload during $\mathrm{N}-2$ contingency is:

$$
R O_{N-2, i}=\left(C 21_{i}-100\right) \cdot C 22_{i}[(\%) \text { of rated capacity } \cdot \text { hours }],(
$$

$i=1 . . N_{B}$

If $N_{\mathrm{s}}$ is the total number of future scenarios of load and conventional and renewable generation sources (including wind power) a and $N_{\mathrm{B}}$ the total number of branches in the system analyzed, then the severity index for each scenario and each branch can be computed as a weighted sum:

$$
\begin{aligned}
& S I_{s, i}=\left[w_{N} \widetilde{R O}_{N, i}+w_{N-1} \widetilde{R O}_{N-1, i}+w_{N-2} \widetilde{R O}_{N-2, i}\right]_{\mathrm{s}}, \\
& \text { where } w_{N}+w_{N-1}+w_{N-2}=1 \\
& \qquad \begin{aligned}
s= & 1 . . N_{s} \\
& i=1 . . N_{B}
\end{aligned}
\end{aligned}
$$

$S I_{s, i}$ is the severity index for scenario $s$ and branch $i ; w_{N}, w_{N-1}$, $w_{N-2}$ are the weighting factors for the $\mathrm{N}, \mathrm{N}-1$ and $\mathrm{N}-2$ situations respectively; $\widetilde{R O}_{N, i}, \widetilde{R O}_{N-1, i}, \widetilde{R O}_{N-2, i}$ are the normalized values of the risks of overload computed in (2), (3) and (4).

The values of the above mentioned weights should be set according to the preferences of the decision-maker and based on the legal requirement for the TSO to ensure the security of electricity supply in the control area under its responsibility. After consulting with transmission planning experts, values in the range of $w_{N}=0.6-0.5, w_{N-1}=0.3-0.4$ and $w_{N-2}=0.1$ were arrived at. Note that the choice of weights will be influencing the ranking order of the various bottlenecks, however all detected overloads are presented to the decision-maker, ordered from most to least severe.

For an overall view, an aggregated severity index for all studied scenarios can be obtained (see Fig. 3), with higher weights assigned to the more likely scenarios. The final severity index of branch $i$ can be computed as:

$$
\begin{aligned}
& S I_{i}=\sum_{j=1}^{N_{s}} w_{j} S I_{j, i}, i=1 . . N_{B} \\
& \sum_{j=1}^{N_{s}} w_{j}=1,
\end{aligned}
$$

where $w_{j}$ are weights assigned to individual future scenarios .

The remaining criteria $(\mathrm{C} 03, \mathrm{C} 13, \mathrm{C} 14, \mathrm{C} 15$ and $\mathrm{C} 23)$ can be further used by the decision makers if more information is needed for prioritizing bottlenecks and recommending solutions for eliminating them.

After obtaining the final bottleneck ranking for all elements in the system some further investigations can be also done. For observing if the voltage is within limits, AC contingency analysis can be performed on some identified critical moments in time. System stability issues can be also investigated if needed for the most critical cases.

\section{METHOD VALIDATION}

\section{A. The New England test system}

As a case study, the 39-bus New England test system is adopted [8]. This system consists of 46 transmission branches (lines and transformers), 10 generators and 39 busses. The system is modified in order to fit the needs of this study (see Fig. 6).

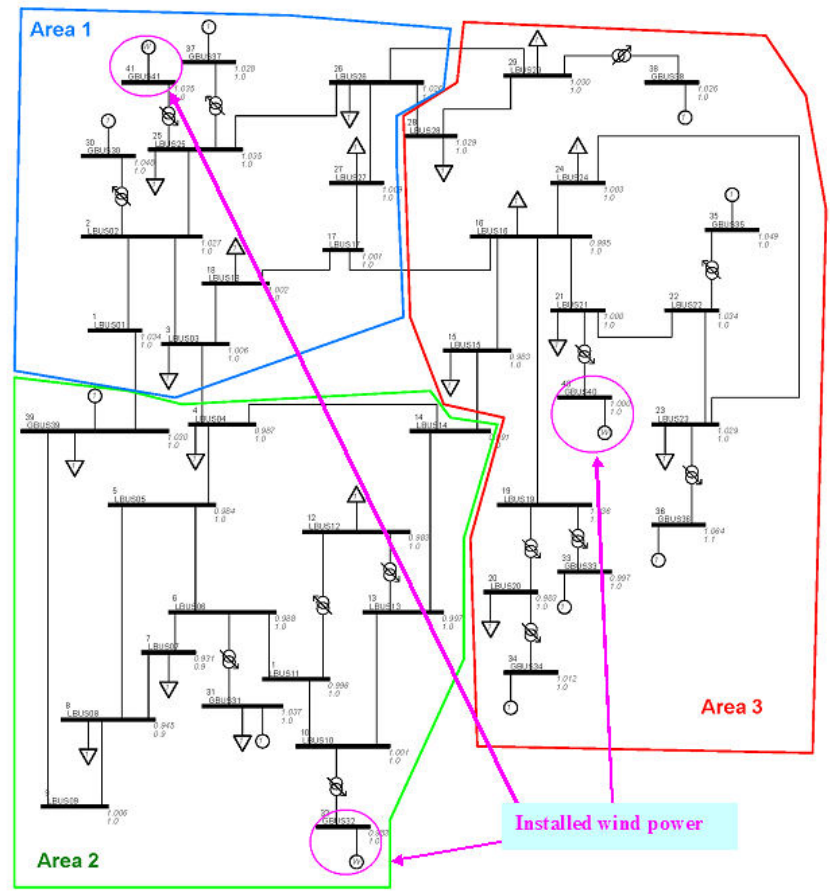

Fig. 6. New England test system

Two more busses - 40 and 41 - are added to the system, and they connect wind power generation to the rest of the system via two new branches (transformers) between buses 41 and 25 and between buses 40 and 21. Therefore the system becomes a 41-bus system with 12 generators, 41 buses and 48 transmission branches. In addition, it is assumed that bus 32 also connects a wind power plant. All branches were assumed to have a rated capacity of $900 \mathrm{MVA}$. 
Furthermore, the system is split up into three interconnected areas - Area 1, Area 2 and Area 3. The three areas are connected by the branches illustrated in Table I.

TABLE I NEW ENGLAND INTERCONNECTORS

\begin{tabular}{|c|c|}
\hline Areas & Branches [bus no. - bus no.] \\
\hline Area $1-$ Area 2 & $1-39 ; 3-4$ \\
\hline Area $1-$ Area 3 & $26-29 ; 26-28 ; 16-17$ \\
\hline Area $2-$ Area 3 & $14-15$ \\
\hline
\end{tabular}

The loads are not fixed to the values given in the original system. Instead, three load curves for one year (hourly values) are taken from a real system and are scaled relative to the peak load values of these time series. These relative values (between 0 and 1) are multiplied by the area total load values specified for the original New England system.

Also, the data for the generators is enhanced and made consistent with current conversion technologies and fuel prices. The types of generators used in the test system are illustrated in Table II. In this table an example of installed wind capacity is given. This example is used for the method validation. Wind power-time series based on measured wind speed data are scaled to the installed wind capacity decided for the studied scenario.

It is important to mention that the load and wind input data are chronological and correlated and span one year of hourly averages.

TABle II Generating Units in New EngLand Test System

\begin{tabular}{|c|c|c|c|}
\hline Area & Plant type & $\begin{array}{c}\text { Installed capacity } \\
{[\mathbf{M W}]}\end{array}$ & $\begin{array}{c}\text { Capacity factor } \\
{[\%]}\end{array}$ \\
\hline Area 1 & Lignite bus 37 & 965 & 85 \\
\cline { 2 - 4 } & Gas bus 30 & 640 & 6 \\
\cline { 2 - 4 } & Wind bus 41 & 300 & 32 \\
\hline Area 2 & Coal bus 39 & 1100 & 39 \\
\cline { 2 - 4 } & Gas bus 32 & $185 * 2$ & 27 \\
\cline { 2 - 4 } & Wind bus 31 & 1600 & 24 \\
\hline Area 3 & Coal bus 38 & 1050 & 68 \\
\cline { 2 - 4 } & Gas bus 33 & $200 * 2$ & 2 \\
\cline { 2 - 4 } & CCGT bus 35 & 790 & 64 \\
\cline { 2 - 4 } & CCGT bus 34 & 625 & 28 \\
\cline { 2 - 4 } & CCGT bus 36 & 699 & 35 \\
\cline { 2 - 4 } & Wind bus 40 & 1600 & 36 \\
\hline
\end{tabular}

After running the market simulations the output of each generating unit is obtained together with other information as exchanges between areas. Within the market simulation transmission capacity limits between the three areas were enforced. Each of these values was chosen to be smaller than the total rated transmission capacity between two areas.

In Table II the capacity factors of each power plant for the studied year are illustrated, whereas Table III presents aggregated information at area level for load, total generation, imports and exports.

The time elapsed for the round-the-year security analysis was 1 hour in the case of the New England test system.
TABLE III GENERATION, LOAD AND EXCHANGE DATA FOR NE

\begin{tabular}{|c|c|c|c|c|}
\hline Area & $\begin{array}{c}\text { Area load } \\
{[\mathbf{G W h}]}\end{array}$ & $\begin{array}{c}\text { Area total } \\
\text { generation }[\mathbf{G W h}]\end{array}$ & $\begin{array}{c}\text { Imports } \\
{[\mathbf{G W h}]}\end{array}$ & $\begin{array}{c}\text { Exports } \\
{[\mathbf{G W h}]}\end{array}$ \\
\hline Area 1 & 7253.5 & 14656 & 83.2 & 7486.3 \\
\hline Area 2 & 13306.1 & 7984.7 & 5383.5 & 64.1 \\
\hline Area 3 & 15280.7 & 13195.2 & 2682.8 & 599.2 \\
\hline
\end{tabular}

\section{B. Detailed security analysis Area 1: comparison with the snapshot method}

In this section a comparison between the snapshot method and the proposed round-the-year method is made in order to show that the year round method gives more complete results. For purposes of illustration this comparison will be shown for Area 1. In Fig. 7 the load curve for Area 1 is represented. Two seasonal peaks - summer (hour 3804) and winter (hour 8466) are identified for the snapshot method.

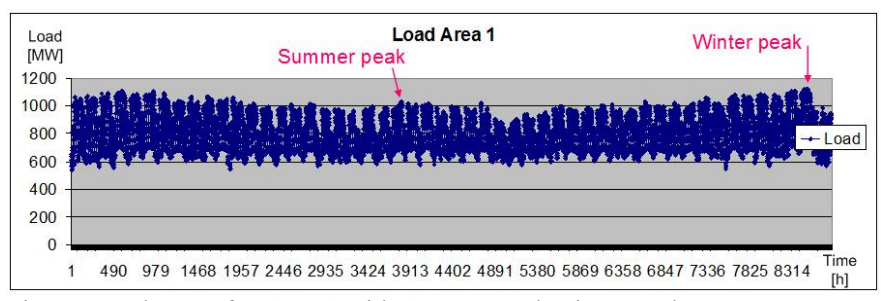

Fig. 7. Load curve for Area 1 with Summer and Winter peak

In Fig. 8 the loadings of the branches belonging to Area 1 are illustrated for the two snapshots in $\mathrm{N}$ and $\mathrm{N}-1$ situations.

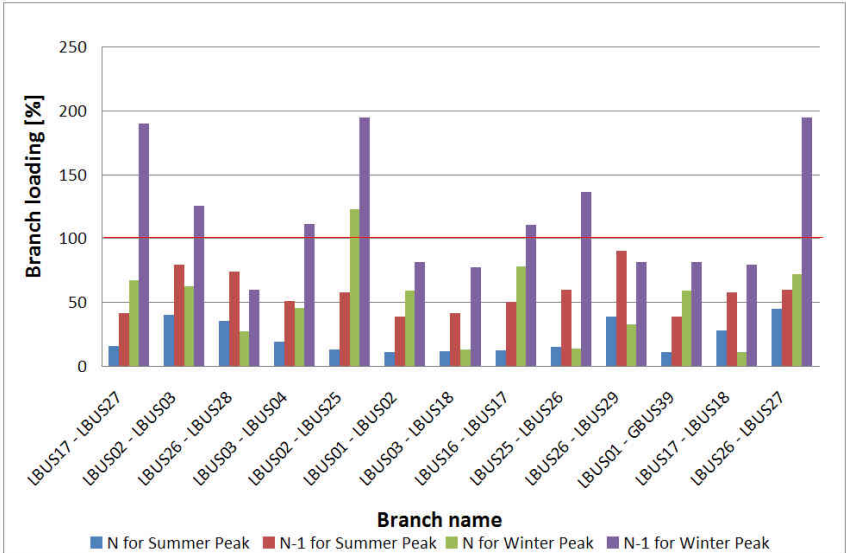

Fig. 8. Area 1 branch loadings for the winter and summer peaks

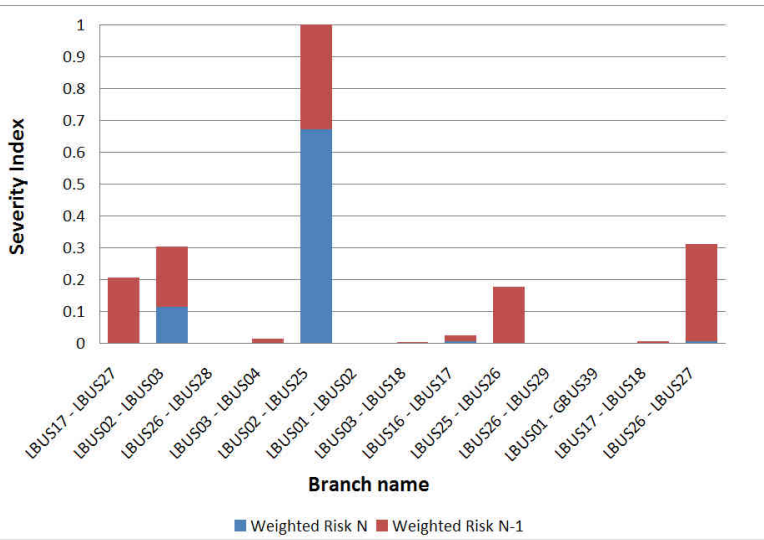

Fig. 9 Final bottleneck ranking for Area 1 
It can be noticed that during the summer peak there are no overloads. The winter peak gives one overloaded branch during the $\mathrm{N}$ situation and 7 overloads for the $\mathrm{N}-1$ contingency analysis.

If in the snapshot method only a few overloads were identified, by using the round-the-year analysis it was noticed that actually in the base case 7 branches are overloaded and in the $\mathrm{N}-1$ case 13 as defined by a positive risk of overload, in comparison to 1 and respectively 7 overloaded branches in the snapshots. Fig. 9 shows the aggregated results for the roundthe-year security analysis. The aggregation was done according to (5) and with the weights for 0.67 for the $\mathrm{N}$ case and 0.33 for the $\mathrm{N}-1$ case.

It can be concluded that the snapshot method misses a number of overloaded branches.

Moreover the ranking of the bottlenecks is also changed. Table IV illustrates the changing in ranking for the top 7 bottlenecks.

TABLE IV TOP 7 BOTTLENECK RANKING FOR AREA 1: SNAPSHOT VS ROUND THE YEAR SECURITY ANALYSIS

\begin{tabular}{|c|c|c|}
\hline Rank & Branch name (snapshot) & Branch name (round the year) \\
\hline 1 & $2-25$ & $2-25$ \\
\hline 2 & $26-27$ & $26-27$ \\
\hline 3 & $17-27$ & $2-3$ \\
\hline 4 & $25-26$ & $17-27$ \\
\hline 5 & $2-3$ & $25-26$ \\
\hline 6 & $3-4$ & $16-17$ \\
\hline 7 & $16-17$ & $3-4$ \\
\hline
\end{tabular}

\section{New England Tie-lines Overview}

The target of the presented security analysis and bottleneck ranking method is international transmission expansion planning. In real-life studies, where individual areas are modeled possibly in a more simplified way, the focus is mainly on interconnectors; also important internal lines can be observed.

Consequently, in this section an overview of the bottleneck ranking results for the tie-lines in the New England system is made. Hence, Fig. 10 and Fig. 11 show the ranking for the base case and for the $\mathrm{N}-1$ situation respectively.

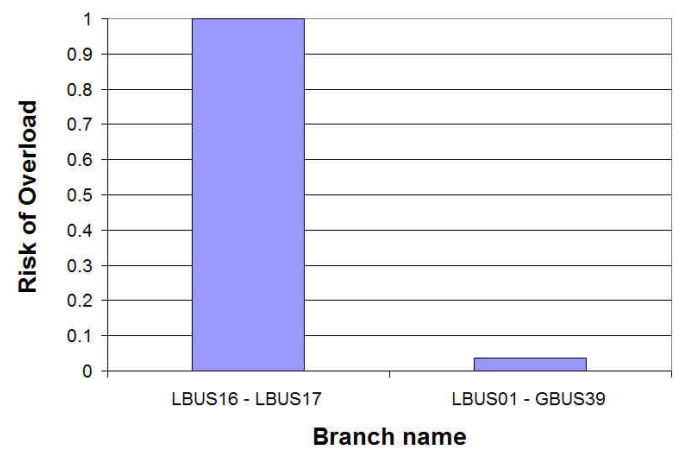

Fig. 10. Tie-lines bottleneck ranking during $\mathrm{N}$ situation according to the risk of overload

The final bottleneck ranking according to the severity index is shown in Fig. 12. The aggregation was done according to (5) and with the weights for $\mathrm{N}$ and $\mathrm{N}-1$ cases 0.67 and 0.33 respectively. All the tie-lines that appear in the three figures are congested as the risk of overload $\mathrm{RO}>0$.

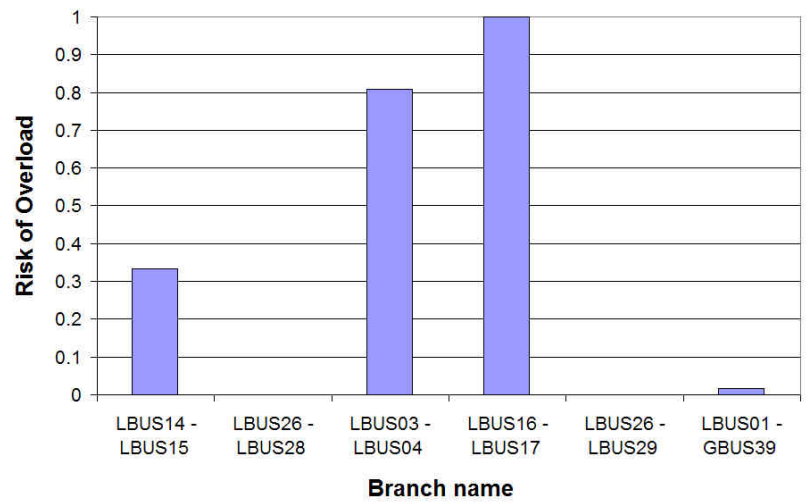

Fig. 11. Tie-lines bottleneck ranking during N-1 situation according to the risk of overload

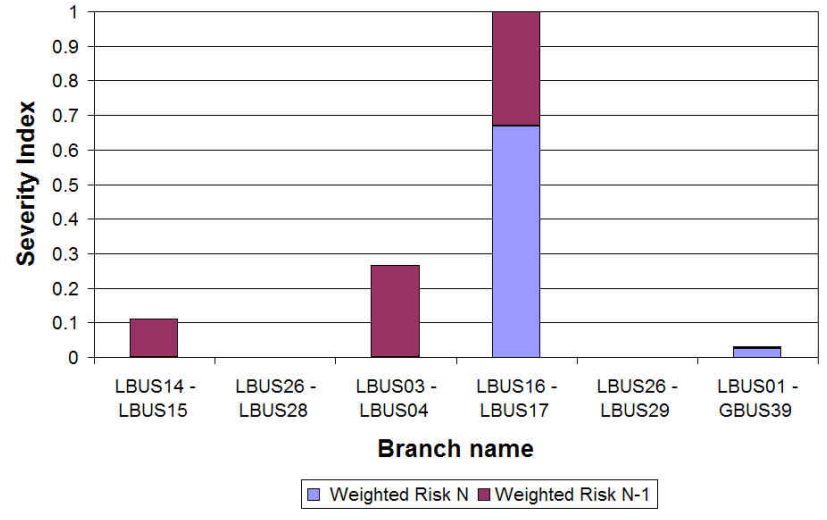

Fig. 12. Final bottleneck ranking for the tie-lines

The top 3 bottlenecks are listed in Table V. By analyzing this table together with the information showed in Table III it can be noticed that the reasons for tie-lines 16-17 and 3-4 being the most congested ones are the high exports from Area 1 to Areas 2 and 3 in combination with the limited available interchange capacity.

TABLE V TOP 3 BOTTLENECK RANKING FOR THE TIE LINES

\begin{tabular}{|c|c|c|}
\hline Rank & Branch name & Between Areas \\
\hline 1 & $16-17$ & Area $1-$ Area 3 \\
\hline 2 & $3-4$ & Area $1-$ Area 2 \\
\hline 3 & $14-15$ & Area 2 - Area 3 \\
\hline
\end{tabular}

\section{CONCLUSIONS}

In this paper a statistical method for bottleneck ranking to be used in transmission expansion planning has been presented. The method uses a round the year approach and is adequate for interconnected power systems that have a high penetration of wind power. Market simulations were combined with detailed load flow calculations for getting a complete picture of the congestions in the transmission grid, while considering the chronological aspect and the correlation of load and wind-speed time series. Criteria for prioritizing bottlenecks were developed together with a method for 
ranking them according to a risk-based severity index.

The method was tested on a modified New England system that includes wind power plants, using one year of load and wind data. The results of the snapshot method and of the proposed round-the-year method were compared for one area. It was shown that the new method gives more accurate results, identifying bottlenecks that the snapshot method missed and also giving a reliable bottleneck ranking based on the risk of overload calculation. In addition, an analysis for all the six tielines of the New England system was made via the proposed method. The top three bottlenecks were identified. The market simulation results regarding the energy exchanges between the three areas justify the presence of congestion in these corridors. The subsequent security analysis pinpoints which physical transmission lines are affected.

\section{ACKNOWLEDGMENT}

The authors gratefully acknowledge the contributions of TSO representatives C. Vergine (TERNA, Italy), K. Reich, O. Wadosch (VERBUND-APG, Austria), and G. De-SaintMartin (RTE, France) for their feedback regarding the method proposed in this work.

\section{REFERENCES}

[1] G. Fulli, A.R. Ciupuliga, A. L'Abbate, and M. Gibescu, "REALISEGRID D3.1.1 Review of existing methods for transmission planning and for grid connection of wind power plants", June 2009, [Online]. Available: http://realisegrid.erse-web.it

[2] R.de Dios, F. Soto, and A.J. Conejo, "Planning to Expand?", IEEE Power \& Energy Magazine, Vol. 5, No. 5, Sept.-Oct. 2007, pp. 64-70.

[3] The EWIS: http://www.wind-integration.eu/

[4] TradeWind: http://www.trade-wind.eu/

[5] P.G.H. Jacobs, C.P.J. Jansen, R. van Offeren, E. Pelgrum, A.R. Ciupuliga, A. Mahes, and M. Gibescu, "A novel transmission system planning method combining market simulations and load flow calculations for identifying bottlenecks in systems with large RES penetration", Paper number C1 202, accepted for CIGRE 2010 Session held in Paris in August 2010

[6] PowrSym3 operation manual: Description of the PowrSym3 computer model, OSA.

[7] K. Dietrich, F. Leuthold, and H. Weigt, "Will the Market Get it Right? The Placing of New Power Plants in Germany", Electricity Markets Working Papers WP-EM-32, April 2009

[8] M. A Pai, "Energy Function Analysis for Power System Stability", Kluwer Academic Publishers, Boston, 1989.

\section{BIOGRAPHIES}

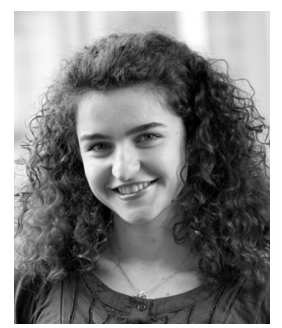

Ana Roxana Ciupuliga received the Dipl.Eng. in Electrical Power Engineering from the University Politehnica, Bucharest, Romania in 2008. Since October 2008 she has been with the Electrical Power Systems group at Delft University of Technology, Delft, The Netherlands, where she is working toward her Ph.D. degree. Her present research interests include transmission expansion planning for large-scale wind integration, sustainability assessment for transmission projects and approval procedures for transmission projects.

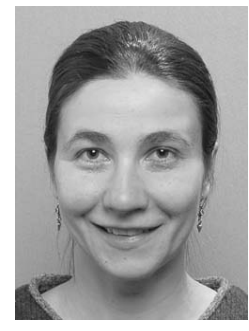

Madeleine Gibescu received the Dipl.Eng. in Power Engineering from the University Politehnica Bucharest, Romania in 1993 and her MSEE and Ph.D. degrees from the University of Washington, Seattle, WA, U.S. in 1995 and 2003, respectively. She has worked as a Research Engineer for ClearSight Systems and as a Power Systems Engineer for the AREVA T\&D Corporation of Bellevue, WA, U.S. She is currently an Assistant Professor with the Electrical Power Systems group at the Delft University of Technology, The Netherlands.

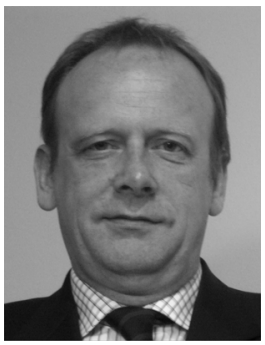

Engbert Pelgrum has received his B.Sc. Degree in Electrical Engineering from the Technical College of Zwolle (the Netherlands). $\mathrm{He}$ is with the Ownership, Business Planning and Regulation department of TenneT B.V., the Dutch Transmission System Operator. $\mathrm{He}$ is responsible for the development of European power market and transmission system simulation models, used in the field of system development and security of supply, as well as for analyses related to the medium and long term development of the Dutch and European power systems. He has over 20 years of experience in the area of chronological system modelling and power system operation and planning for the Dutch and foreign generation and transmission systems.

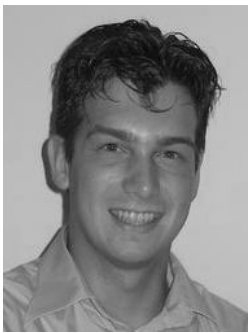

Pim G.H. Jacobs received his M.Sc degree in electrical engineering from the Eindhoven University of Technology, The Netherlands in 2005. He works with the Dutch Transmission System Operator (TenneT TSO) since. His current position is network analyst at the Asset Management Department where the main activities are in long term EHV planning, national and international

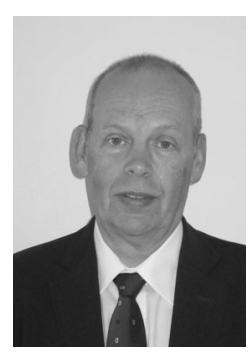

Kees P.J. Jansen received the M.Sc. degree in electrical engineering from the Eindhoven University of Technology, the Netherlands, in 1982. In 1983 he started at ASEA Sweden at the High Voltage Department. In 1986 he moved to KEMA in the Netherlands at the Consulting Department. In that function he was involved in a large number of system studies for both industrial grids and for the network of the national System Operator. In 2006 he joined the Dutch Transmission System Operator (TenneT). The current position within TenneT is a senior network analyst at the Asset Management Department. In that function he is involved in studies related to short term and long term network planning.

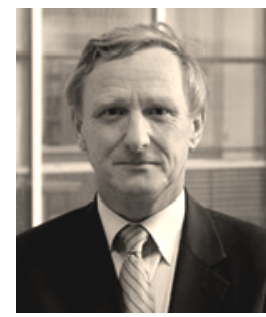

Wil L. Kling received the M.Sc. degree in electrical engineering from the Eindhoven University of Technology, the Netherlands, in 1978. From 1978 to 1983 he worked with Kema, from 1983 to 1998 with Sep and since then up till the end of 2008 he was with TenneT, the Dutch Transmission System Operator, as senior engineer for network planning and network strategy. Since 1993 he is a part-time Professor at the Delft University of Technology and since 2000 also at the Eindhoven University of Technology, The Netherlands. From December 2008 he is appointed as a full Professor and chair of Electrical Power Systems group at the Eindhoven University of Technology. He is leading research programs on distributed generation, integration of wind power, network concepts and reliability issues. Prof. Kling is involved in scientific organisations such as Cigré and IEEE. $\mathrm{He}$ is the Dutch Representative in Study Committee C6 Distribution Systems and Dispersed Generation and the Administrative Council of Cigré. 